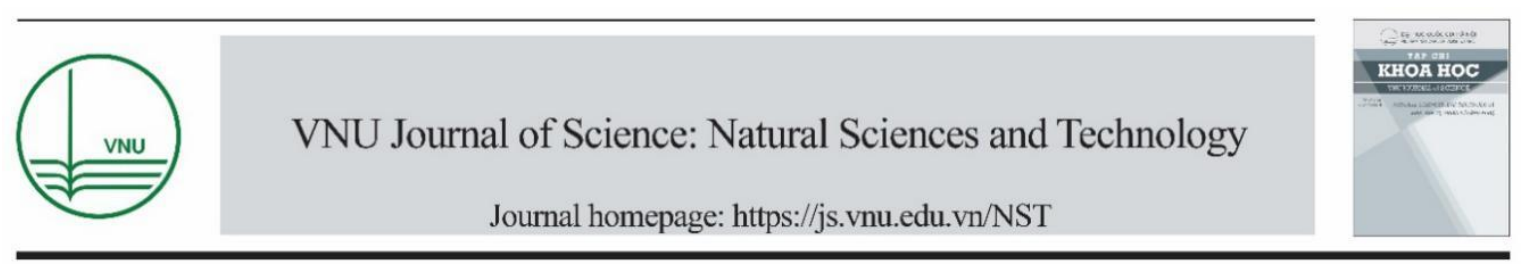

\title{
Original Article \\ Synthesis and Characterization of a Highly Ordered Mesoporous Bio-glass
}

\author{
Bui Xuan Vuong ${ }^{1, *}$, Ngo Thi My Thanh ${ }^{2}$ \\ ${ }^{1}$ Faculty of Pedagogy in Natural Sciences, Sai Gon University, 273 An Duong Vuong, \\ District 5, Ho Chi Minh City, Vietnam \\ ${ }^{2}$ Faculty of Chemical Technology and Food, Ho Chi Minh City Industry and Trade College, \\ 20 Tang Nhon Phu, District 9, Ho Chi Minh City, Vietnam
}

Received 17 November 2019

Revised 09 December 2019; Accepted 10 January 2020

\begin{abstract}
A highly ordered mesoporous bio-glass has been successfully prepared by the sol-gel method, in which copolymer pluronic P123 was used as a structure-creating template. The obtained material has the mesoporous structure with the high value of specific surface area $\left(395.6 \mathrm{~m}^{2} / \mathrm{g}\right)$ and the $2 \mathrm{D}$ hexagonal pore architecture with the pore sizes from 5.5 to $7 \mathrm{~nm}$. The "in vitro" experiment was effectuated by soaking the bio-glass powder in the simulated body fluid (SBF). The obtained results confirmed the bioactivity of the synthetic biomaterial through the quick formation of a hydroxyapatite layer after 1 day of immersion.
\end{abstract}

Keywords: Bio-glass, pore size, mesoporous, bioactivity, "in vitro”.

\section{Introduction}

Bio-glasses are a group of surface-reactive materials that can form a hydroxyapatite (HA) layer when they are soaked in physiological medium or implanted in the human body [1]. Hydroxyapatite phase is the main component of bone mineral, so it acts as an active link between artificial materials and bone tissue, through which the bone defects can be repaired and replaced [2]. The ability to form HA mineral, also called the bioactivity is an important property of bio-glasses and can be controlled by the "in vitro" test in the simulated body fluid (SBF) or by the "in vivo" experiment in the animal body $[2,3]$. When the HA layer grows as a function of times, the bio-glasses dissolve completely and a new bone matrix is formed without any residue of the starting biomaterials at the end [2-3]. There are different bio-glasses, which have been studied and developed in the past few decades such as bio-glasses $45 \mathrm{~S} 5,46 \mathrm{~S} 6$,

\footnotetext{
* Corresponding author.

Email address: buixuanvuongsgu@ gmail.com

https://doi.org/10.25073/2588-1140/vnunst.4975
} 
58S, 70S30C, S53P4, etc. [1-3]. Two main processes can synthesize these biomaterials, including melting and sol-gel methods. The melting method can synthesize bio-glasses in a short time, about several hours, by heating the starting precursors at high temperatures, following a special regime [4]. Although the melting technique is a quick method, the obtained glasses usually have low values of specific surface area. According to the previous studies, the value of the specific surface area is the key factor, influencing the bioactivity of the bio-glasses $[5,6]$. The increase in specific surface area can enhance the surface reactions between the artificial materials and the physiological environment, thereby increasing the formation of the HA layer. The sol-gel method can synthesize the bio-glasses at lower temperatures. Especially, the obtained bioglasses can have porous structures and high values of specific surface area that improve the bioactivity of the synthetic materials [7]. To enhance the porous structure and specific surface area of the bio-glasses synthesized by sol-gel method, Pluronic P123-a non-ionic block copolymer of poly(ethylene oxide)-poly (propylene oxide) - poly(ethylene oxide) $\left[\mathrm{HO}\left(\mathrm{CH}_{2} \mathrm{CH}_{2} \mathrm{O}\right)_{20} \quad\left(\mathrm{CH}_{2} \mathrm{CH}\left(\mathrm{CH}_{3}\right) \mathrm{O}\right)_{70}\right.$ $\left.\left(\mathrm{CH}_{2} \mathrm{CH}_{2} \mathrm{O}\right)_{20} \mathrm{H}\right]$ has often been used as a structure-creating template [8-10]. The selfassembly property of this organic compound leads to the highly ordered mesostructure of the synthetic bio-glasses. Depending on the composition of the synthetic bio-glasses and the added amount of the structure-directing agent, the obtained bio-glasses have different properties of pore size, pore-volume, and specific surface area, which influenced the bioactivity ability of the final bio-glasses [9-10]. In this work, the bio-glass $58 \mathrm{~S}$ with the composition of $58 \mathrm{SiO}_{2}-33 \mathrm{CaO}-9 \mathrm{P}_{2} \mathrm{O}_{5}$ (wt.\%) has been synthesized by the modified sol-gel method. The highly ordered mesostructure of synthetic bio-glass was obtained by using Pluronic P123 as a structure-creating template. The template P123 was added in the synthetic bio-glass with a mass ratio of $1 / 1$. The properties of the obtained bio-glass such as structure morphology, chemical phase and "in vitro" bioactivity have been investigated.

\section{Materials and Methods}

\subsection{Materials}

The main chemicals used to prepare the highly ordered mesoporous bio-glass included tetraethyl orthosilicate (TEOS) (reagent grade, 98\%, Sigma-Aldrich); triethyl phosphate (TEP) (reagent grade, $99.8 \%$, Merck); calcium nitrate tetrahydrate $\mathrm{Ca}\left(\mathrm{NO}_{3}\right)_{2} .4 \mathrm{H}_{2} \mathrm{O}$ (regent grade, $99 \%$, Sigma-Aldrich) and poly (ethylene oxide)-poly (propylene oxide)-poly (ethylene oxide) (Pluronic $\mathrm{P} 123$, chemical formula as $\mathrm{HO}$ $\left(\mathrm{CH}_{2} \mathrm{CH}_{2} \mathrm{O}\right)_{20}\left(\mathrm{CH}_{2} \mathrm{CH}\left(\mathrm{CH}_{3}\right) \mathrm{O}\right)_{70}\left(\mathrm{CH}_{2} \mathrm{CH}_{2} \mathrm{O}\right)_{20} \mathrm{H}$, molecular weight of $5800 \mathrm{~g} / \mathrm{mol})$.

\subsection{Preparation of highly ordered mesoporous bio-glass}

The highly ordered mesoporous bio-glass with the composition of $58 \mathrm{SiO}_{2}-33 \mathrm{CaO}-9 \mathrm{P}_{2} \mathrm{O}_{5}$ (wt. \%) was synthesized with the amounts of reactants presented in Table 1 . The chemical precursors were originally calculated to synthesize 2 grams of bio-glass material. Based on the scientific references [11-13], the synthetic processing is briefly described as follows. The mixture of calculated amounts of TEOS and TEP in distilled water was stirred for 30 minutes with the stirring speed of $100 \mathrm{rpm}$. The nitric acid $2 \mathrm{M}$ $\mathrm{HNO}_{3}$ was used to adjusting the $\mathrm{pH}$ of the reaction mixture as 1.5 . After that, the calcium nitrate tetrahydrate was added and the reaction mixture kept stirring for 30 minutes. At the end of this time, a clear sol was formed. The amount of P123 was dissolved in the above sol. The mixture was kept in 3 days at room temperature to form the gel. The gel was aged for 2 days at $60^{\circ} \mathrm{C}$ and then dried at $100^{\circ} \mathrm{C}$ for 1 day. The dried gel was treated at $700^{\circ} \mathrm{C}$ for 3 hours to combust the $\mathrm{P} 123$ template and convert into the glass powder. 
Table 1. Nominal composition (wt. \%) and amounts of reactants (g) of the synthetic bio-glass

\begin{tabular}{ccccccc}
\hline Sample & Nominal composition $(\% \mathrm{wt})$ & $\begin{array}{c}\text { TEOS } \\
(\mathrm{g})\end{array}$ & $\begin{array}{c}\mathrm{TEP} \\
(\mathrm{g})\end{array}$ & $\begin{array}{c}\mathrm{Ca}\left(\mathrm{NO}_{3}\right)_{2} .4 \mathrm{H}_{2} \mathrm{O} \\
(\mathrm{g})\end{array}$ & $\begin{array}{c}\mathrm{H}_{2} \mathrm{O} \\
(\mathrm{g})\end{array}$ & $\begin{array}{c}\mathrm{P} 123 \\
(\mathrm{~g})\end{array}$ \\
\hline $58 \mathrm{~S}$ & $58 \mathrm{SiO}_{2}-33 \mathrm{CaO}-9 \mathrm{P}_{2} \mathrm{O}_{5}$ & 4.03 & 0.47 & 2.81 & 14.62 & 2 \\
\hline
\end{tabular}

\section{3. “In vitro" experiment}

The bioactivity of the synthetic bio-glass was investigated via the "in vitro" test. The powder of bio-glass sample was soaked in the SBF solution in a ratio of $1 / 2(\mathrm{mg} / \mathrm{mL})$. The SBF solution used in this study was prepared in the laboratory according to Kokubo's method [14]. The ionic composition of the SBF solution is similar to that of the blood in the human body. The reactive mixture was stirred at a speed of 50 rpm for 1 to 15 days. At the end of immersed time, the powder was rinsed with distilled water and then dried at $100^{\circ} \mathrm{C}$. The obtained powder was used for phase identification.

\subsection{Physical-chemical characterization}

The values of specific surface area, pore size, and pore volume were identified by the $\mathrm{N}_{2}$ adsorption-desorption measurement on micromeritics ASAP 2010. The BET (Brunauer - Emmett - Teller) method was used to determine the specific surface area. The pore volume and pore size were achieved from the desorption branch of the isotherm by the $\mathrm{BJH}$ (Barret - Joyner - Halenda) method. For morphological analysis of glass samples, scanning electron microscopy (SEM) (JEOL JMS 6301) and field emission - scanning electron microscopy (FE - SEM) (JEOL JMS $7200 \mathrm{~F}$ ) were used to evaluate the surface morphologies; transmission electron microscopy (TEM) (JEOL JEM 2100) was performed to observe the internal structure. To evaluate the phase structure of the synthetic bio-glass before and after "in vitro" experiment, X-ray diffraction (XRD) measurement were obtained from a powder diffractometer (Bruker D8 Advance). The XRD data were acquired in the range of $10-70^{\circ}(2 \theta)$ with a scanning speed of $1 \%$ min. The $\mathrm{pH}$ and $\mathrm{Si}, \mathrm{Ca}, \mathrm{P}$ concentration behaviors versus immersion times during the in vitro test were identified by using the $\mathrm{pH}$ meter and inductively coupled plasma optical emission spectrometry (ICP-OES) (ICP 2060) technique.

\section{Results and discussion}

\subsection{Nitrogen adsorption/desorption analysis}

Nitrogen adsorption/desorption isotherm of the synthetic sample was determined as seen in Figure 1. It could be mentioned that the curve of the sample exhibits the type IV isotherm in the range of relative pressure $\mathrm{P} / \mathrm{P}^{0}$ from 0.7 to 1 , which highlighted the mesoporous structure of the synthetic bio-glass. On the other hand, type $\mathrm{H}_{1}$ of the hysteresis loop is characteristic of opened cylindrical pores in the structure of synthetic bio-glass. The BJH analysis showed the pore size distribution of the synthetic bioglass centered at $6.5 \mathrm{~nm}$ as seen in Figure 2. The specific surface area $\left(\mathrm{S}_{\mathrm{BET}}\right)$ and pore volume value $\left(\mathrm{V}_{\mathrm{p}}\right)$ of the synthetic bio-glass were 395.6 $\left(\mathrm{m}^{2} / \mathrm{g}\right)$ and $0.52\left(\mathrm{~cm}^{2} / \mathrm{g}\right)$, which are significantly higher than those achieved for conventional solgel bio-glasses of similar compositions $[9,10,13]$.

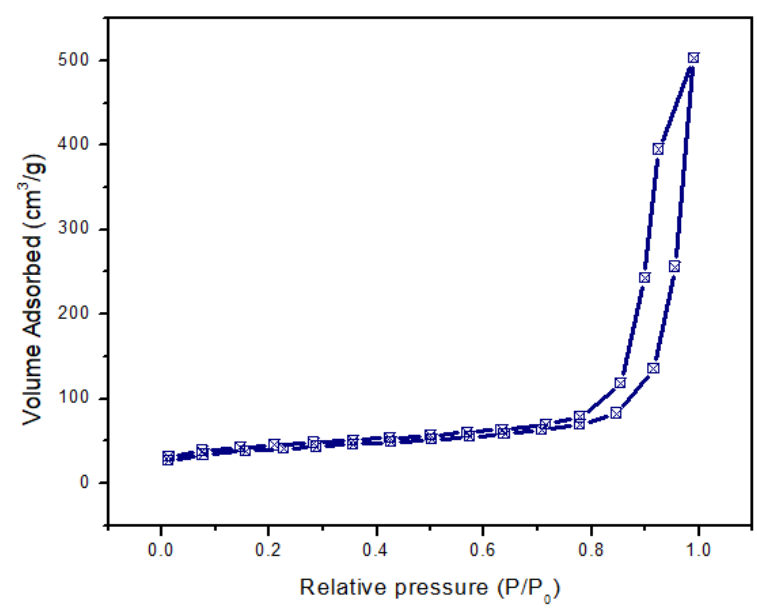

Figure 1. Nitrogen adsorption/desorption isotherm plot of the synthetic bio-glass. 


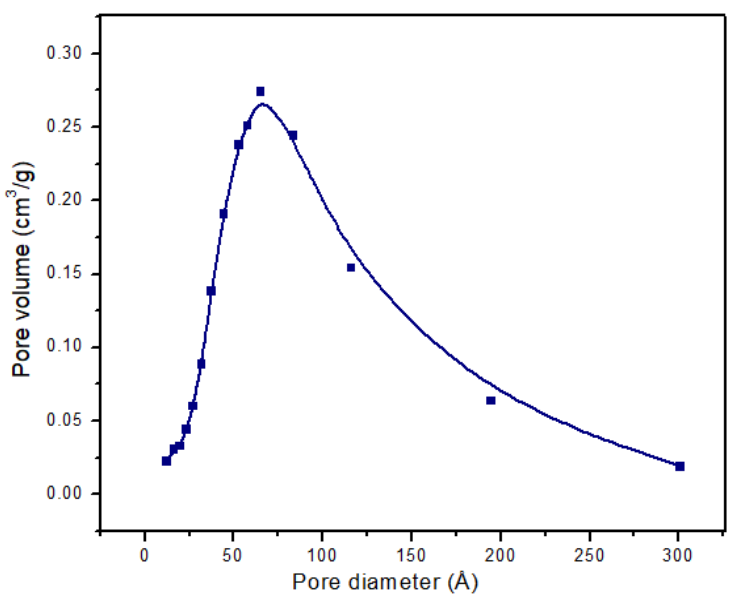

Figure 2. Pore size distribution curve of the synthetic bio-glass.

\subsection{Structural observation}

The morphology of the synthetic bio-glass was investigated by using the FE-SEM and TEM observations as seen in Figure 3. The FE-SEM image showed the spherical morphology in the nano-scale, in which the individual particles were agglomerated to form the interconnected porous structure of the obtained material. The TEM analysis highlighted the existence of a long ordered distance with the 2D hexagonal structured porosity. In addition, the pores were quite uniform in size and shape with the pore sizes in the range from 5.5 to $7 \mathrm{~nm}$.
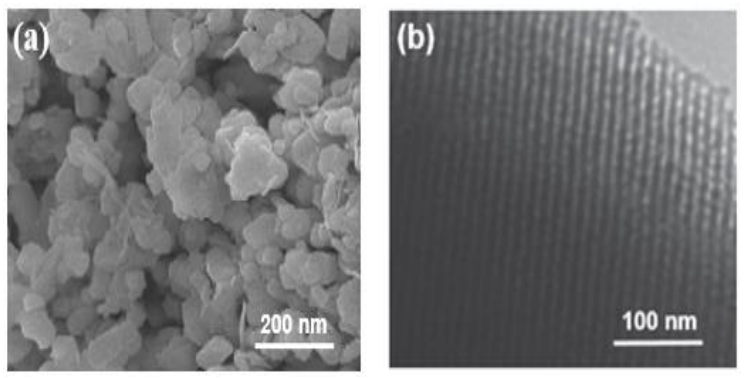

Figure 3. Morphology of the synthetic bio-glass (a) FE-SEM and (b) TEM images.

\subsection{Investigation of "in vitro" bioactivity}

The bioactivity is the ability to form hydroxyapatite (HA) layer on the glass surface after "in vitro" experiment at several times. The XRD spectra from 1 day to 15 days were almost similar in appearance. Therefore, the spectrum for 1 day was selected to compare with the one of synthetic bio-glass, as seen in Figure 4. The initial sample showed a broad peak, centered at around $23^{\circ}(2 \theta)$. This feature of the XRD diagram is characteristic of an amorphous material. The bio-glass sample revealed two well-define crystalline peaks at about 26 and $32^{\circ}$ (20) after 1 day of "in vitro" experiment. This confirmed the chemical reactions between the bio-glass sample and the SBF environment, leading to the transformation from the amorphous phase to the crystalline phase. By comparison with the XRD standard diagram of the HA material (JCPDS 90432), the two observed peaks are attributed to the formation of HA crystals on the surface of the bio-glass sample. They are corresponding to (002) and (211) crystalline plans in the HA crystalline structure, respectively. The appearance of the new HA phase confirmed the high bioactivity of the synthetic bio-glass. The highly ordered mesoporous structure and high value of specific surface area may be the main factors, enhancing the surface reactions, leading to the quick formation of a hydroxyapatite layer after only 1 day of the "in vitro" test.

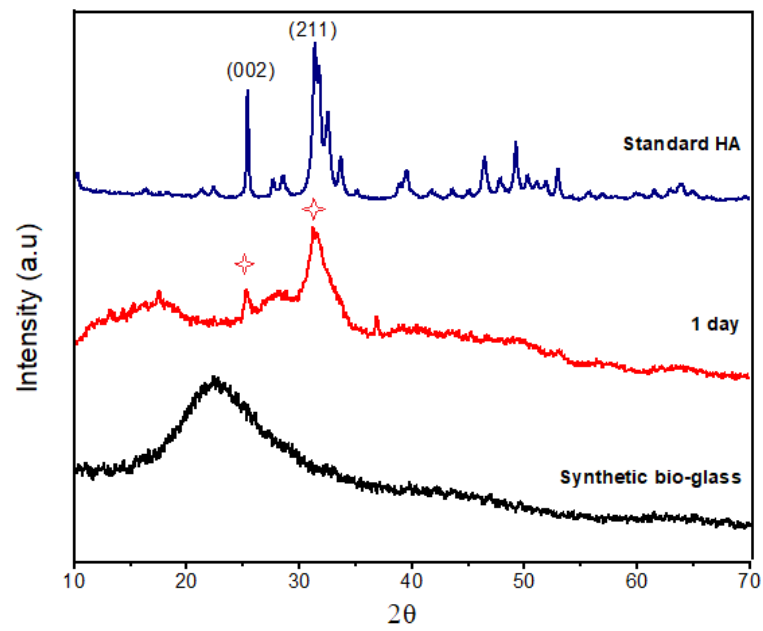

Figure 4. XRD patterns of the synthetic bio-glass before and after 1 day of "in vitro" test. 
To observe the formation of the HA layer on the surface of the glass sample, the SEM images at different magnifications of the synthetic bioglass before and after 1 day of the "in vitro" test in the SBF solution are presented in Figure 5. The surface of the initial synthetic bio-glass was quite smooth (Figure 5a) while the smalluniform crystals were covered on one of the bioglass after soaking in the SBF solution (Figure 5b1-3). The obtained result confirmed the chemical interaction between the surface of the material and the SBF environment. This leads to forming the HA layer on the surface of the bioglasses [3,4]. In comparison with the previous studies $[4,9,13]$, the synthetic bio-glass expressed the high bioactivity via a quick formation of a new-apatite layer after only 24 hours of the "in vitro" experiment.

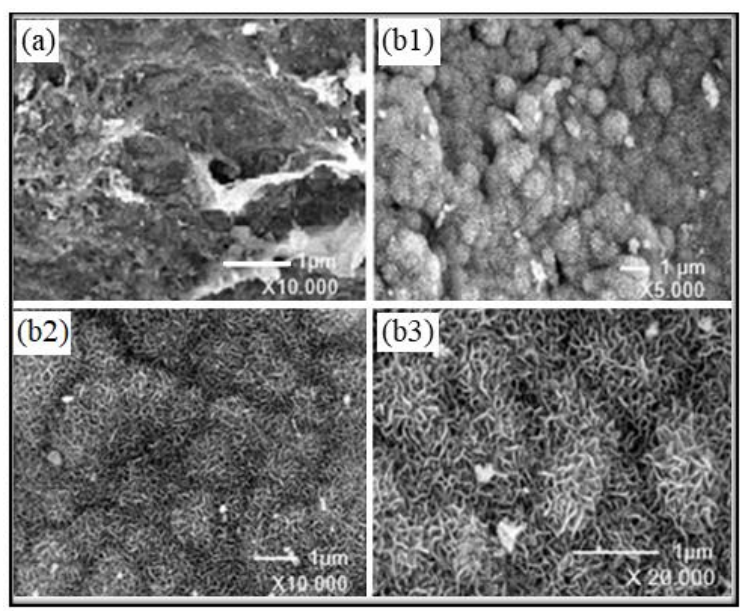

Figure 5. SEM observation of the synthetic bio-glass (a)-initial sample and (b1, b2, b3)-samples at different magnifications after 24 hours of immersion in the SBF solution.

\subsection{Behaviors of ionic exchange between bio- glass and SBF solution}

Figure 6 presents the ionic behaviors in the SBF solution as a function of immersion time, identified by the ICP-OES method. According to the scientific papers, the ionic changes in the physiological media are related to the surface reactions between the bio-glass and the SBF solution $[3,8,9,13]$.
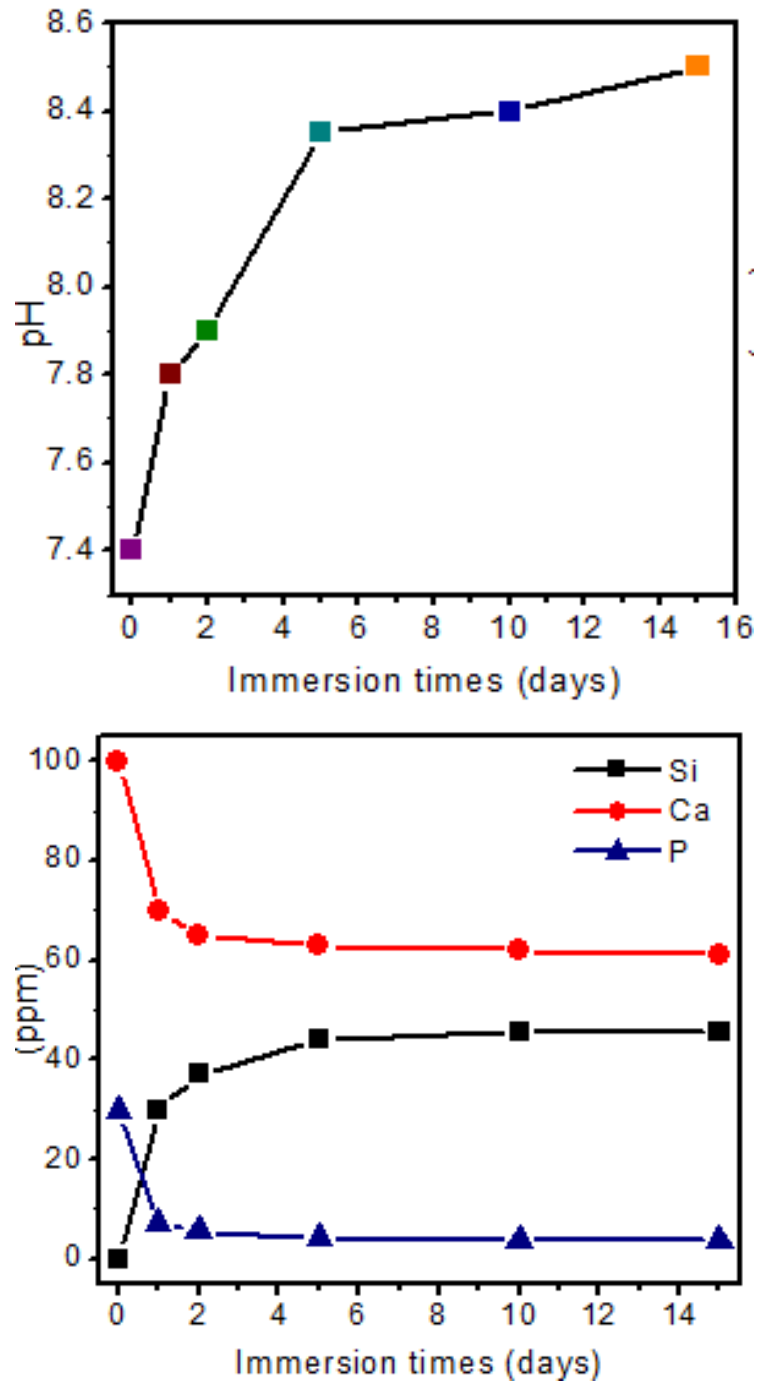

Figure 6. Ionic concentrations of the SBF solution during "in vitro" experiment.

For $\mathrm{pH}$, a significant increase was observed during the first five days of immersion. This observation corresponds to the quick ion exchange of $\mathrm{Ca}^{2+}$ out of the bio-glass and $\mathrm{H}^{+}$in the SBF solution as the following reaction:

$$
(-\mathrm{O}-\mathrm{Si}-\mathrm{O}-) \mathrm{Ca}^{2+}+\mathrm{H}^{+} \rightarrow-\mathrm{Si}-\mathrm{OH}+\mathrm{Ca}^{2+}(1)
$$

The consumption of $\mathrm{H}^{+}$leads to an increase in $\mathrm{pH}$ value. After this period, the $\mathrm{pH}$ value was almost constant due to the end of reaction 1 .

A similar behavior of Si concentration in the SBF solution was observed. It began with a 
period of strong increase, and then reached a saturated step. The increase of $\mathrm{Si}$ in the SBF solution is related to the breaking of $-\mathrm{Si}-\mathrm{O}-\mathrm{Si}-$ $\mathrm{OH}$ to release the soluble silicic $\mathrm{Si}(\mathrm{OH})_{4}$.

$$
-\mathrm{Si}-\mathrm{O}-\mathrm{Si}-\mathrm{OH}+\mathrm{H}_{2} \mathrm{O} \rightarrow \mathrm{Si}(\mathrm{OH})_{4}
$$

The pursuit of reaction 2 was the repolymerization of silicic acid to form $\mathrm{SiO}_{2}$ - rich layer on the surface of the glass sample.

The existence of $\mathrm{Ca}$ and $\mathrm{P}$ in the $\mathrm{SBF}$ solution consists of two sources. The first one is the $\mathrm{Ca}, \mathrm{P}$ components available in the initial SBF solution. The second one is the $\mathrm{Ca}, \mathrm{P}$ amounts released by the reaction of glass with SBF solution. According to reaction 1 , the $\mathrm{Ca}$ concentration in the SBF solution will increase. However, a significant decrease in the $\mathrm{Ca}$ component was identified during the whole immersion process. In addition, a similar observation was also noted for $\mathrm{P}$ behavior. This phenomenon is due to the consumption of $\mathrm{Ca}$ and $\mathrm{P}$ to precipitate the apatite layer on the glass surface. The consumption of $\mathrm{Ca}$ and $\mathrm{P}$ in the first day is most obvious, confirming the high bioactivity of the synthetic bio-glass. After 1 day of "in vitro", the $\mathrm{Ca}, \mathrm{P}$ concentrations were almost stable while the $\mathrm{pH}$ value increased until 5 days. This phenomenon can be explained by the continuous degradation of bio-glass under reaction 1 , simultaneously with the association of $\mathrm{Ca}$ and $\mathrm{P}$ components to form the HA layer on the surface of the glass sample. The obtained result is consistent with the above analysis by the $\mathrm{XRD}$, in which the HA phase was formed after only 1 day of immersion.

\section{Conclusion}

Copolymer pluronic P123 was used as a structure-creating agent to prepare the ternary bio-glass $58 \mathrm{SiO}_{2}-33 \mathrm{CaO}-9 \mathrm{P}_{2} \mathrm{O}_{5}$ (wt.\%) by using the sol-gel method. The synthetic bio-glass showed the highly ordered mesoporous morphology with the high value of the specific surface area and the pore sizes in the range from 5.5 to $7 \mathrm{~nm}$. "In vitro" test was effectuated by the immersion of bio-glass powder in the SBF solution. The bioactivity of synthetic bio-glass was confirmed by the quick formation of the hydroxyapatite phase on its surface after only one day of the "in vitro" experiment.

\section{Acknowledgements}

This research is funded by Sai Gon University under the contract number 871/HĐĐHSG and project code CS2019-04.

\section{References}

[1] L.L. Hench, The story of Bioglass, Journal of Materials Science: Materials in Medicine, 17 (11) (2006) 967-978. https://doi.org/10.1007/s10856006-0432-z.

[2] J.R. Jones, Review of bioactive glass: from Hench to hybrids, Acta Biomaterialia, 9 (2013) 44574486. https://doi.org/10.1016/j.actbio.08.023.

[3] H. Oudadesse, E. Dietrich, X.V. Bui, Y.L. Gal, P. Pellen, G. Cathelineau, Enhancement of cells proliferation and control of bioactivity of strontium doped glass, Applied Surface Science, 257 (20) (2011) 8587-8593. https://doi.org/10. 1016/j.apsusc.2011.05.022.

[4] O. Peitl, E.D. Zanotto, F.C. Serbena, L.L. Hench, Compositional and microstructural design of highly bioactive $\mathrm{P}_{2} \mathrm{O}_{5}-\mathrm{Na}_{2} \mathrm{O}-\mathrm{CaO}-\mathrm{SiO}_{2}$ glassceramics, Acta Biomaterialia, 8 (1) (2012) 321332. https://doi.org/10.1016/j.actbio.2011.10.014.

[5] Z. Hong, A. Liu, L. Chen, X. Chen, X. Jing, Preparation of bioactive glass ceramic nanoparticles by combination of sol-gel and coprecipitation method, Journal of NonCrystalline Solids, 355 (6) (2009) 368-372. https://doi.org/10.1016/j.jnoncrysol.2008.12.003.

[6] M. Vallet-Regi, Evolution of bioceramics within the field of biomaterials, Comptes Rendus Chimie, 13 (1) (2010) 174-185. https://doi.org/10.1016/ j.crci.2009.03.004.

[7] G.J. Owens, R.K. Singh, F. Foroutan, M. Alqaysi, C.M. Han, C. Mahapatra, H.W. Kim, J.C. Knowles, Sol-gel based materials for biomedical applications, Progress in Materials Science, 77 (2016) 1-79. https://doi.org/10.1016/j.pmatsci. 2015.12.001.

[8] K. Huang, S. Cai, G. Xu, M. Ren, X. Wang, R. Zhang, S. Niu, H. Zhao, Sol-gel derived mesoporous $58 \mathrm{~S}$ bioactive glass coatings on AZ31 magnesium alloy and in vitro degradation behavior, Surface and Coatings Technology, 240 
(2014) 137-144. https://doi.org/10.1016/j.surfcoat. 2013.12.026.

[9] M.E. Galarraga-Vinueza, J. Mesquita-Guimaraes, R. S. Magini, J. C. M. Souza, M. C. Fredel, and A. R. Boccaccini, "Mesoporous bioactive glass embedding propolis and cranberry antibiofilm compounds," Journal of Biomedical Materials Research: Part A, vol. 106 (6) (2018), pp. 16141625. https://doi.org/10.1002/jbm.a.36352.

[10] D. Arcos, A. Lopez-Noriega, E. Ruiz-Hernandez, O. Terasaki, M. Vallet-Regi, Ordered mesoporous microspheres for bone grafting and drug delivery, Material Chemistry, 21 (6) (2009) 1000-1009, 2009. https://doi.org/10.1021/cm801649z.

[11] D. Arcos, and M. Vallet-Regi, "Sol-gel silicabased biomaterials and bone tissue regeneration,'
Acta Biomaterial, vol. 6 (8) (2010) 2874-2888. https://doi.org/10.1016/j.actbio.2010.02.012.

[12] A. Anand, V. Lalzawmliana, V. Kumar, P. Das, K.B. Devi, A.K. Maji, B. Kundu, M. Roy, S.K. Nandi, Preparation and in vivo biocompatibility studies of different mesoporous bioactive glasses, Journal of the Mechanical Behavior of Biomedical Materials, 89 (2019) 89-98. https://doi.org/10. 1016/j.jmbbm.2018.09.024.

[13] X.V. Bui, T.H. Dang, Bioactive glass 58S prepared using an innovation sol-gel process, Processing and Application of Ceramics, 13 (1) (2019) 98103. https://doi.org/10.2298/PAC1901098B.

[14] T. Kokubo, H. Takadama, How useful is SBF in predicting in vivo bone bioactivity, Biomaterials, 27 (15) (2006) 2907-2915. https://doi.org/10.1016/j. biomaterials.2006.01.017. 